\title{
CLOSE ENCOUNTER WITH A BOBCAT
}

WAYNE HARRIS, 3460 Cowie Crescent, Swift Current, Saskatchewan. $\mathrm{S} 9 \mathrm{H} 4 \mathrm{~W} 1$

I would like to pass on to you a rather unique wildlife experience that I had on 11 July 1993 in the Cypress Hills Provincial Park.

I had spent a very leisurely and enjoyable three hours of a Sunday afternoon travelling the back road between the main park area and Fort Walsh. The wildflowers were exceptional and I couldn't go very far before I spotted another kind I hadn't photographed yet. The end of this journey brought me to the conglom- erate cliffs where I stopped my car on the trail at the top of the cliff and stepped to the edge to look out over the lake and valley below.

To my surprise I heard a sound like a dirt bike seeming to come from the hills across the valley. No movement could be seen there and as I searched I quickly realized the sound came from much closer. I looked down and there on a grassy shelf about $60 \mathrm{ft}$. away sat a Bobcat looking at me. He was growling at me

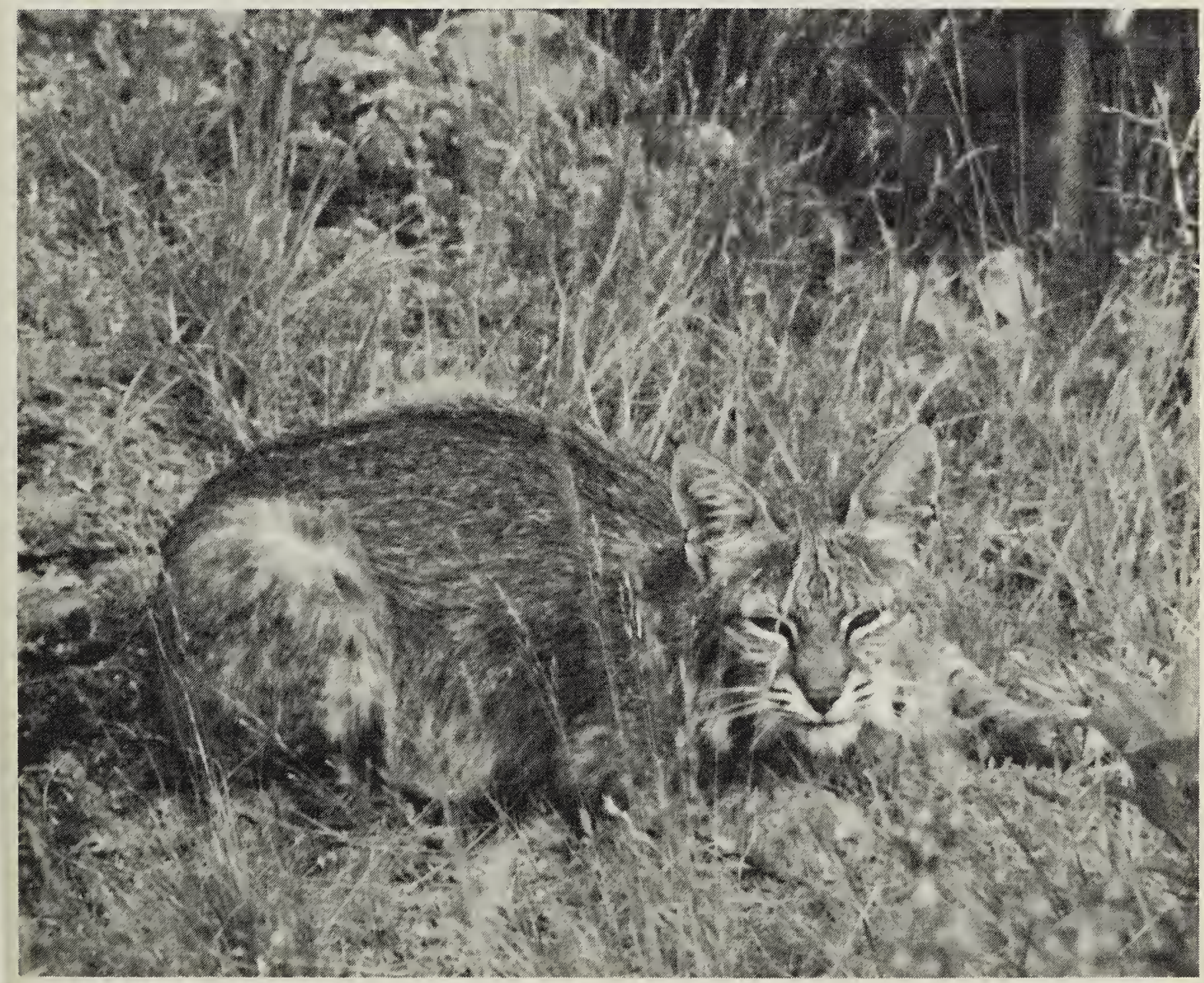




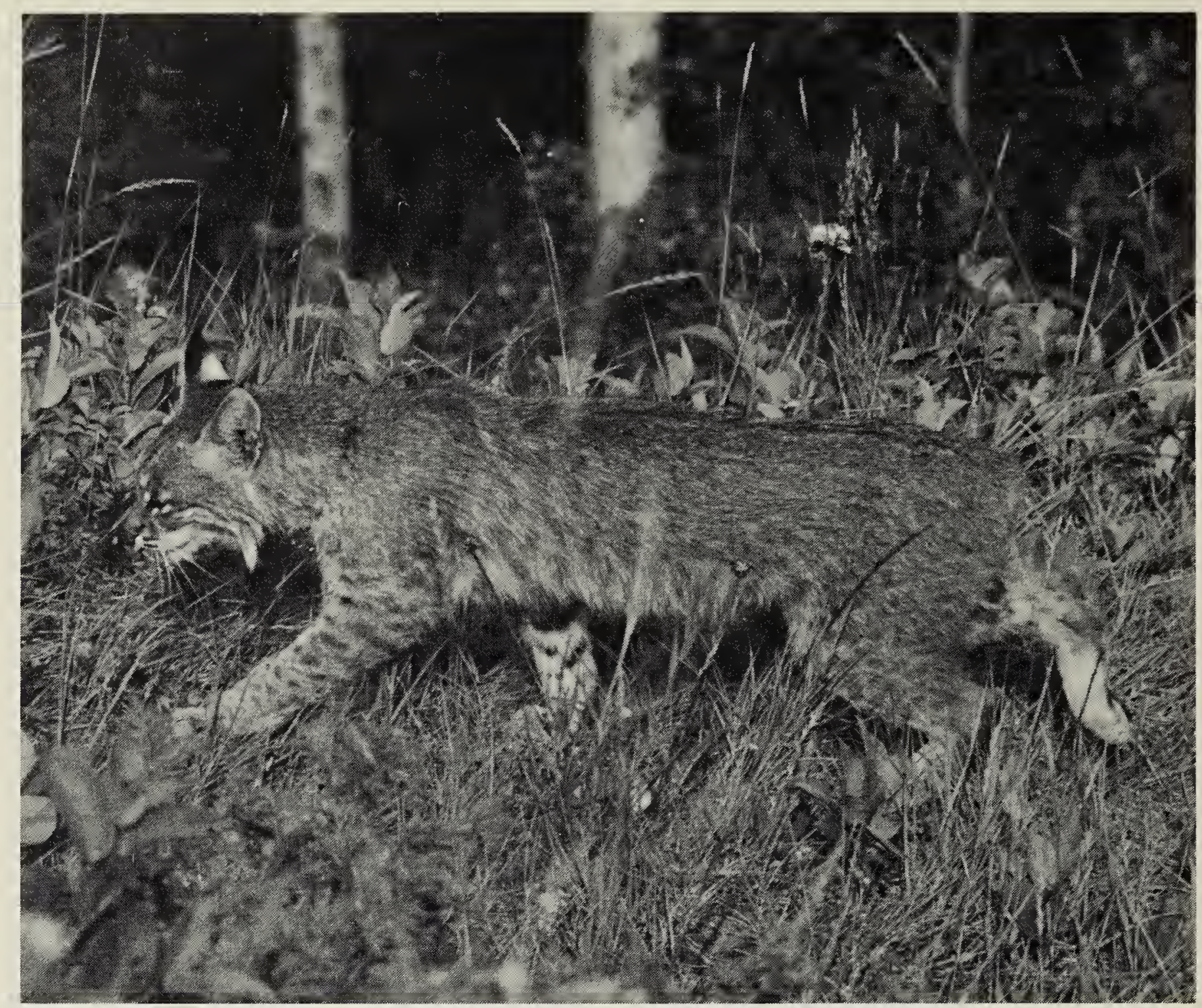

Bobcat

Wayne Harris

and this was the sound that had attracted my attention. After taking a brief look I quietly slipped back to my car, put the telephoto lens on the camera and carefully edged back to take a couple of quick pictures before he left. He was still there and, in fact, hadn't moved at all.

He had not moved after the first few frames and I got bolder and moved to the edge of the cliff and to several spots on the edge. There was no cover there and I was in full view at all times. Other than the growl, he showed no fear or concern for my presence. In fact, he even closed his eyes several times and I would have to make a noise to get him to open them for a picture. He shifted position a few times but never made any motion to leave. After about 20 minutes he moved slowly towards me and approached within $30 \mathrm{ft}$. before moving under the edge of the cliff, but still remaining in sight.

My film was all used up and I had some deadlines to meet so it was time for me to return. I left with a memorable first-time encounter with a Bobcat and enough pictures to relive the moment any time I wanted. 